Association for Information Systems AIS Electronic Library (AISeL)

1984

\title{
Personal Information Systems for Strategic Scanning in Turbulent Environments: Can The CEO Go On-Line?
}

Omar A. El Sawy

University of Southern California

Follow this and additional works at: http://aisel.aisnet.org/icis 1984

\section{Recommended Citation}

El Sawy, Omar A., "Personal Information Systems for Strategic Scanning in Turbulent Environments: Can The CEO Go On-Line?" (1984). ICIS 1984 Proceedings. 7.

http://aisel.aisnet.org/icis1984/7 


\title{
Personal Information Systems for Strategic Scanning in Turbulent Environments: Can The CEO Go On-Line?
}

\author{
Omar A. El Sawy \\ Center for Futures Research \\ Graduate School of Business Administration \\ University of Southern California
}

\begin{abstract}
Empirical evidence suggests that scanning for information becomes an increasingly salient activity for top executives as enviromental turbulence increases. A critical part of scanning for top executives in such environments is scanning to identify strategic threats and opportunities. This is the focus of this paper. We seek to understand the strategic scanning behaviors of top executives in order to provide some guidelines for designing computerbased systems to support and enhance strategic scanning processes.

The paper first tries to understand the characteristics of the strategic scanning process through an empirical study of 37 chief executive officers (CEOs) of small to medium-sized high technology companies in northern California's Silicon Valley. Through a semi-structured interview with the flavor of an event protocol, the CEOs were asked about various aspects of their strategic attention behavior in relation to three strategic threats and opportunities which they were experiencing. Several general questions pertaining to their use of information sources for strategic information were also asked.

Information sources were classified based on the location of the information source (external or internal to the organization), and based on the directional specificity of information transmission (personal or impersonal). The results showed that the CEOs relied to a greater extent on external sources for the strategic information, than they did on internal sources. The results indicate that they did not frequently delegate scanning for strategic information to their subordinates or assistants, nor were they willing to do so. The results also showed that the CEOs used more personal than impersonal information sources for strategic information, and that the number of sources was limited. These results in combination suggest that the CEO's personal scanning filter (rather than the organizational filter) is of prime importance in identifying strategic issues.
\end{abstract}

Two types of strategic scanning information were identified by the CEO's. The first type was general surveillance information which was not necessarily coupled with any specific threat or opportunity, but which changed the frame of reference through which they interpreted further information, implying that second-order learning is a feature of the strategic scanning process. The second type was information coupled to identifying specific threats or opportunities.

Four modes of strategic scanning were identified: routine monitoring, problemistic search, unsolicited reception, and coincidental surveillance. The results showed that the strategic information scanning method was more often proactive than reactive, and that CEO's most frequently used the routine monitoring mode for strategic scanning, indicating that they are very systematic scanners, and that there are certain habitual sources that the CEO monitors and consults.

The paper then draws some conclusions and implications for the design of computer based information systems for supporting strategic scanning. The empirical results suggest that in

*This paper is forthcoming in MIS Quarterly. 
terms of strategic attention, the CEO's information system is very personal and somewhat decoupled from the organizational information system. Thus a computer-based information system to support and enhance the CEO's strategic scanning would probably have to be a customized personal system, with inputs being made by the CEO himself. This points in the direction of some kind of "tickler file" system which has some very simple input methods, but sophisticated classification and manipulation capabilities with qualitative verbal data. The emergence of "idea outlining" software is a step in that direction. A further step would be to incorporate some learning features into the software to adapt to changing frames of reference. Given the absence of the tight coupling requirement between a strategic scanning system and the organizational system, and given the small database, portable lap computers are identified as an appropriate medium for such an application. 